\title{
EDITORIAL
}

\section{CREACIÓN DE LA FACULTAD DE ENFERMERÍA DE LA UNIVERSIDAD DE CONCEPCIÓN}

\section{CREATION OF THE UNIVERSITY OF CONCEPCION FACULTY OF NURSING}

\author{
Dra. Viviane Jofré Aravena \\ Decana (I) Facultad de EnFermería. Universidad de Concepción
}

Enfermería ha ido evolucionando a través del tiempo y se ha ido transformando de oficio o vocación en profesión. Como disciplina está fundamentada en un conocimiento propio, en su desarrollo histórico y un ejercicio profesional definido (1).

Para la Organización Mundial de la Salud, Enfermería abarca la atención autónoma y en colaboración, a personas de todas las edades, familias, grupos y comunidades, sanas o enfermas, y en todas circunstancias. Esta atención es entregada tanto para la promoción de la salud, la prevención de enfermedades y el cuidado de enfermos, discapacitados y personas en la etapa final de la vida (2).

Es precisamente el ejercer la profesión a partir de un conocimiento específico que es propio de una disciplina, lo que permite establecer la diferencia entre el ejercicio profesional y el ejercicio disciplinar. En el caso de Enfermería, se han planteado los elementos metaparadigmáticos o conceptos esenciales: Enfermería-cuidado, salud, persona y entorno, como los ejes que permiten establecer lineamientos para comprender el ser, el saber y el quehacer y se acepta que la profesión solo puede avanzar si se asume como una disciplina que analiza, profundiza y crea conocimientos aplicables a un quehacer en forma permanente, reflexiva y crítica (3 - 6).

La Educación Superior de las Enfermeras en Chile tiene un historial de cien años. Desde sus inicios, ha tenido un reconocido nivel de excelencia, contando con profesionales que manejan un amplio cuerpo de conocimientos, un apreciable conjunto de habilidades y destrezas técnicas, administrativas y de gestión, dando como resultado un profesional integral y altamente competente en cualquier nivel de atención, cuyo aporte al mejoramiento de los indicadores de salud del país ha sido de gran importancia. Más aún cuando dicho aporte se ha realizado en el marco de una escasez permanente de enfermeras y enfermeros. 
La unidad académica de Enfermería de la Universidad de Concepción tiene un desarrollo de 67 años, en los cuales hemos recorrido un largo y fructífero camino. Han sido muchos los logros que nos acompañan, que indudablemente ha sido con el esfuerzo de muchas y muchos colegas que tuvieron la visión y el liderazgo de sembrar en las mentes de las diversas generaciones el espíritu que le otorga sentido a la enfermería y, por otra parte, de todos los que actualmente estamos trabajando y que hacemos los máximos esfuerzos para enseñar e investigar, aportando a dar soluciones a las necesidades de la sociedad actual y al crecimiento de nuestra disciplina, acrecentando el legado heredado y haciendo historia para las futuras generaciones (7).

Es en este transitar que, desde hace un poco más de dos décadas, hemos venido planteando la necesidad de autogobierno, estando ciertas/os de las capacidades que la unidad académica posee. Es así que durante los últimos 3 años hemos vuelto a diseñar estrategias y gestiones para conseguir la tan ansiada autonomía administrativa y académica.

Consideramos que poseemos el perfil que se necesita para ser Facultad, pues ésta se considera como tal cuando, aparte de poseer la atribución o potestad legalmente reconocida para otorgar grados académicos, supone que se les considera autoridades calificadas para certificar la calidad de la formación y de los conocimientos de sus propios egresados.

Es así como orgullosamente expresamos que la Universidad de Concepción ha decretado, con fecha 7 de abril, la creación de la Facultad de Enfermería.

Este hito en la historia de la enfermería no es sólo nuestro, es de todo el colectivo de enfermeras de nuestra región y del país, pues esto permitirá continuar con la consolidación en el ámbito disciplinar y profesional, a través del desarrollo del pensamiento crítico, conocimiento sólido en la disciplina, formación de agentes de cambio con una firme estima profesional y con confianza en sí mismos y de su rol en los equipos de trabajo donde le corresponde actuar. A su vez, con el aporte del postgrado para la formación de líderes, investigadores de enfermería, innovadores en el cuidado, como respuesta a las necesidades de un mundo globalizado. Hemos asumido un gran desafío, sin embargo nuestra fortaleza radica fundamentalmente en nuestro pilar disciplinar, el cuidado como objeto de la disciplina y de la praxis, asumiendo que esto también implica modificar nuestra manera de pensar, de ser y de hacer enfermería, para ser profesionales autónomos, responsables de nuestros actos con una praxis fundamentada tanto en evidencias científicas como en la sensibilidad y la creatividad, comprometida con la construcción de condiciones de vida favorables para las comunidades. 


\section{REFERENCIAS}

1. Cabal V, Guarnizo M. Enfermería como Disciplina. Revista Colombiana de Enfermería. 2007; 6(6): 73-81.

2. Organización Mundial de la Salud. Enfermería [Internet]. Temas de salud en enfermería; [citado 23 abril 2015] Disponible en: http://www.who.int/topics/ nursing/es/.

3. Bonder G. Construyendo el protagonismo de las mujeres en la sociedad de conocimiento: estrategias educativas y de formación de redes. Bilbao: Unesco; 2003.

4. Burbano C. Una mirada actual de la simbología en enfermería. Colom Med. 2007; 38 (4, supl. 2): 105-109.

5. Sanabria U, Otero M, Urbina LO. Los paradigmas como base del pensamiento actual en la profesión de enfermería. Rev Cubana Edu Med Supe. [Internet]. 2002 [citado 23 abril 2015]; 16(4). Disponible en: http://bus.sld.cu/revistas/ ems/vol16_4_02/ems07402.htm

6. Stiepovich, J. Desarrollo de enfermería como disciplina. Cienc. enferm. 2002; VIII (1): 7.

7. Paravic T. 65 años de la carrera de Enfermería de la Universidad de Concepción. Concepción, Chile. Cienc. enferm. 2012; XVIII (2): 7-9. 